\title{
A INTENCIONALIDADE DO SISTEMA EDUCACIONAL AO DETERMINAR QUEM E O QUE SE APRENDE
}

\section{ARTIGO ORIGINAL}

PEREIRA, Katty Oliveira Silva ${ }^{1}$

PEREIRA, Katty Oliveira Silva. A intencionalidade do sistema educacional ao determinar quem e o que se aprende. Revista Científica Multidisciplinar Núcleo do Conhecimento. Ano 05, Ed. 05, Vol. 05, pp. 84-96. Maio de 2020. ISSN: 2448-0959, Link de acesso: https://www.nucleodoconhecimento.com.br/educacao/sistemaeducacional

\section{RESUMO}

A partir das teorias sobre o desenvolvimento da aprendizagem surgidas no século $X X$, destacamos as ideias do Behaviorismo e da Gestalt na tentativa de decifrar como o indivíduo aprende e de importantes colaboradores como Piaget, Vygotsky e Bruner que ajudaram a entender a formação dos processos cognitivos. Buscamos entender o posicionamento das diferentes investigações sobre a aprendizagem utilizando uma análise comparativa entre os autores citados, através de uma revisão bibliográfica a fim de constatar o porquê do sistema educacional ainda padecer pela ineficiência do rendimento escolar dos alunos nas diversas faixas etárias, nos levando a refletir porque os estudos sobre a aprendizagem serviram de base para o controle de quem e o que se aprende.

Palavras-chaves: Aprendizagem, sistema educacional, controle.

${ }^{1}$ Doutoranda em Ciências da Educação pela Universidade Nacional de Rosário/ Argentina, Mestranda em Educação Superior pela Universidade Nacional de Rosário/ Argentina e Pedagoga pela Universidade Salvador/ Brasil. 


\section{INTRODUÇÃO}

Este artigo tem por objetivo identificar as pesquisas que surgiram em torno dos processos de aprendizagem a partir de uma breve análise histórica sobre os estudos desenvolvidos pelo Behaviorismo[2] e pela Gestalt[3], além de observar as contribuições realizadas por especialistas no assunto como Piaget[4], Vygotsky[5] e Bruner[6] para refletir criticamente porque há tanto investimento para entender os processos cognitivos da aprendizagem se o sistema educacional a quem deveria estar destinado essas pesquisas para melhorar o desempenho dos alunos continuam padecendo com problemas básicos que se estendem desde a formulação do currículo até a infraestrutura escolar interferindo negativamente na aprendizagem.

Refletir sobre as contribuições da psicologia da educação em desvendar os processos que as crianças experimentam ao longo do desenvolvimento se tornou um suporte da pedagogia, mas é importante que os atores da educação entendam por que essa parceria por si só não tem garantido o sucesso escolar.

\section{DESENVOLVIMENTO}

Quando analisamos o contexto histórico dos estudos sobre o comportamento humano percebemos uma evolução na maneira de olhar os processos de aprendizagem. $\mathrm{O}$ interesse por esse estudo surgiu a partir da analises do comportamento animal, com a publicação da Revista Cientifica de Psicologia Animal em 1900, na França. Logo depois, inicia-se o estudo do comportamento humano, onde no primeiro momento a tendência era estudar os processos mentais "no vazio", quer dizer, isolados dos contextos sociais (COLOMBO, 2001). As investigações sobre a aprendizagem percorreram um longo caminho, passando por diferentes estudos que serão analisadas até se chegar a um consenso da interferência que o contexto social provoca no indivíduo. 


\subsection{BEHAVIORISMO}

O interesse era transformar a Psicologia em ciência, deixando de lado especulações e ideias intangíveis como o termo alma, consciência e mente, já que não podiam ser medidas.

Segundo Topf (2006, p. 41) Watson se destaca nesse cenário, defendendo a ideia que "conduta é aquilo que um organismo faz em forma de comportamento externo, visível", por isso cria os problemas que fundamentam o Behaviorismo entendendo que uma resposta é provocada por um estimulo e que era necessário observar como essa resposta foi aprendida.

Esses problemas levantaram uma série de hipóteses até se chegar à ideia principal que as respostas são baseadas em condicionamentos, transformando esses estudo em "um estudo analítico de consciência mediante a introspecção" (COLOMBO, 2001, p. 19). Foram desenvolvidos a partir daí uma série de testes e experimentos, mas todos em laboratórios, limitando seu campo de estudo. Pérez Gómez (1993) explica que Pavlov[7] e Skinner[8] utilizam aportes que são 'aspectos parciais de processos de aprendizagem' e que 'a aprendizagem não pode ser entendida como uma simples relação de entradas e saídas' referindo-se ao estimulo/resposta, que ocorre segundo o autor, porque 'tem uma mediação que transforma'. Ajudando a entender que o e Behaviorismo elimina a complexidade dos processos da aprendizagem.

\subsection{GESTALT}

Seu estudo foi iniciado por Wertheimer[9] na Alemanha quando inventou um experimento chamado estroboscópio, que mostrava uma ilusão ou 'movimento aparente' sendo explicado segundo Colombo (2001, p. 35) como 'produto do equilíbrio logrado entre interações e forças presentes entre o campo atual temporal e espacial da experiência'. Essa explicação toma por base a ideia que não é o passado que influência a percepção do indivíduo, mas o campo onde ele está inserido. 
A ideia chave de Kohler[10] (1948) que "o todo é mais que a soma das partes", se tornou uma afirmativa importante para explicar o todo como ponto de partida das experiencias psicológicas e jamais como ponto de chegada.

A Gestalt definiu algumas leis para compreender o funcionamento cerebral que regem o campo perceptual, adotando um enfoque estruturalista, buscando compreender as expressões do ponto de vista dinâmico, deixando de lado as experiencias anteriores, buscando métodos de observação e experimentação, sem fragmentação das mesmas.

Sua influência foi destacada nos estudos da personalidade, motivação, psicologia social e dinâmicas grupais. A Gestalt se destacou do Behaviorismo ao entender que a inteligência criativa está além da inteligência de reprodução.

\subsection{PIAGET, VYGOTSKY E BRUNER}

Segundo Colombo (2001, p. 42) "Piaget destruiu a concepção da ilogicidade do pensamento infantil. Pode mostrar que o pensamento lógico tem um longo processo de construção que antecede inclusive as etapas de manifestação da conduta linguística." Essa buscar para entender o processo de construção do pensamento infantil levou o pesquisador a ter como pergunta norteadora: como se passa de um estado de menor conhecimento a um estado de maior conhecimento?' A busca por resposta surgiu através da observação em crianças que deu origem a Psicologia Genética.

Colombo (2001, p. 48) nos explica que "para Piaget o conhecimento não é um estado e sim um processo ativo". Esse conhecimento é despertado a partir da interação entre sujeito e objeto. Para compreender como ocorre esse processo Piaget estuda as estruturas que formam as categorias cognoscitiva, explicando o sujeito epistêmico "os mecanismos comuns a todos os sujeitos individuais do mesmo nível". A sua ideia se centra em buscar as características comuns aos indivíduos e não suas peculiaridades. Por isso, desenvolve o estudo das estruturas cognoscitivas, estabelecendo fases do 
desenvolvimento que explicam as interferências que ocorrem através da mediação no comportamento do indivíduo que possibilita seus avanços e retrocessos.

Foi assim que determinou que existe um período de assimilação, acomodação e adaptação para que ocorra processos intelectuais de acordo com organizações superiores do pensamento. Denominou os estados do desenvolvimento intelectual como períodos de inteligência sensório-motor, de período de inteligência representativa e período de inteligência operatória: concreta y formal, sendo que uma sucede a outra, ampliando o grau de maturidade da criança.

Piaget ainda aponta a afetividade e a motivação como importantes fatores para o desenvolvimento, segundo Colombo (2001, p. 74) "Para Piaget é a dimensão energética de todo comportamento, pois não existe nenhuma conduta humana, por intelectual que ela seja que não implique fatores afetivos". Os aspectos afetivos são fundamentais nos processos de mediação, influenciando os processos de aprendizagem.

Vygotsky por sua vez buscou descontruir a ideia que se pode estudar o homem separado de seu contexto social. Colombo (2001) explica que:

A proposta de Vygotsky para a compreensão da mente humana oferece uma perspectiva nova que parte do suposto de que toda função intelectual deve se explicar a partir de sua relação essencial com as condições históricas y culturais (COLOMBO, 2001, p. 78).

Vygotsky buscou uma linha de pensamento inovadora para sua época, buscando entender tudo como em constante movimento e mudança baseando-se na ideia de que entre a mediação há instrumentos e signos, interconectado a vida social do indivíduo, acreditando que havia a dimensão biológica, a dimensão histórica e a cultural que o sujeito está inserido, interpretando como as transformações nesse contexto modificavam o comportamento dos indivíduos. $\mathrm{O}$ autor destaca a linguagem como eixo importante para o desenvolvimento humano e a importância da interação no processo de aprendizagem. 
Colombo (2001, p. 111) explica que para Vygotsky "boa aprendizagem é aquela que se origina a partir da educação assistida pelo adulto, o companheiro mais capaz." A partir dessa ideia define o conceito de Zona de desenvolvimento proximal e real, mostrando o que a criança é capaz de fazer sozinha e o que pode alcançar com a ajuda do outro.

Bruner por sua vez, em suas investigações também foca seu trabalho em como funciona a mente a partir das ferramentas à disposição, de uma dependência com a cultura. $\mathrm{O}$ autor explica que "a aprendizagem e o pensamento sempre estão situados em um contexto cultural e sempre dependem da utilização de recursos culturais" (BRUNER, 1996, p. 22). Isto ocorre porque as comunidades criam e transformam os significados das coisas.

A educação é citada por Bruner como cultura que reflete a distribuição do poder, por isso ele acredita que o ensino deve ajudar o aluno a aprender a perguntar, pois assim poderia descobrir o melhor caminho para aprender. Também concorda que as emoções estão ligadas a construção da realidade, defendo a ideia de que "a educação é uma importante encarnação da forma de vida de uma cultura, não simplesmente a preparação para ela". (BRUNER, 1996, p. 31). Essa concepção nos ajuda a entender a perspectiva psicocultural da educação, refletindo na importância da mesma na vida do indivíduo e da sociedade, por isso se tornou conhecido pela sua proposta de "revolução cultural".

Segundo Bruner o sujeito codifica e classifica os dados que chegam do entorno através das categorias das que dispõe para compreendê-lo, já Piaget disse que se tratava de uma revolução cognitiva.

Tendo seus estudos voltados para o âmbito educacional, Bruner (1997) explica:

O aluno não deve falar de física, história, matemáticas... sem fazer física, história ou matemáticas. O conhecimento verdadeiramente adquirido é aquele que se redescobre. Um currículo se baseia em 
passos sucessivos por um mesmo domínio de conhecimento e tem o objetivo de promover a aprendizagem (BRUNER, 1997, p. 24).

Esta ideia originou o conceito de 'currículo em espiral' que defende que o aprendiz constrói seu aprendizado segundo seu próprio intelecto que vai se modificando a partir da interação com o ambiente, aprofundando mais e melhor o conhecimento correspondente ao desenvolvimento cognitivo do aluno.

Esses três pensadores, influenciaram de forma significativa o entendimento sobre os processos de aprendizagem, possibilitando que educadores compreendam a importância de respeitar o nível de maturidade do aluno, valorizando o processo de interação e a fala, além de permitir o processo de experimentação para aquisição da aprendizagem significativa.

\section{A QUEM INTERESSA ENSINAR E APRENDER}

Todas as investigações realizadas sobre o processo da aprendizagem serviram para orientar intervenções educativas, para ajudar os professores nos desafios diários que se encontram na sala de aula, cada uma, com seus diferentes pontos de vista contribuíram e deixaram lacunas, entretanto analisar criticamente cada uma dessas teorias nos conduzirá a compreender os interesses por trás dessas pesquisas. Segundo Pérez Gómez (1993):

As teorias do condicionamento operante têm contribuído poderosamente a compreensão de fenômenos de aquisição, retenção, extinção e transferência de determinados tipos simples de aprendizagem ou de componentes importantes de todo processo de aprendizagem (PÉREZ GÓMEZ, 1993, p. 38).

De maneira rasa, o Behaviorismo possibilitou entender e produzir determinados fenômenos do processo de aprender, com um campo de estudo limitado, não percebeu que a aprendizagem vai além de um processo mecânico que associa através de estimulo, resposta e recompensas. 
Para explicar sobre a Gestalt, Pérez Gómez (1993) esclarece:

Consideram a aprendizagem como um processo de doação de sentido, de significado as situações em que se encontra o indivíduo. Por debaixo das manifestações observáveis se desenvolvem processos cognitivos de discernimento e busca intencional de objetivos e metas (PÉREZ GÓMEZ, 1993, p. 41).

A Gestalt compreendeu que a aprendizagem depende também das forças que interagem ao redor do indivíduo, modificando suas percepções e o conduzindo a produzir atitudes dominadas por essas influências.

Pérez Gómez (1993, p. 43) explica que quando Piaget surge no cenário, nos deixa sua profunda contribuição da psicologia genética explicando que "a aprendizagem é tanto um fator como um produto do desenvolvimento". Se estabelece que nesse processo ocorre a maturação, experiencia física, interação social e equilíbrio, para então a aprendizagem acontecer utilizando instrumentos e intervenções que contribuam com o desenvolvimento.

Vygotsky por sua vez contribui com esclarecimentos a partir da Zona de Desenvolvimento Potencial e Proximal, estabelecendo a relação entre a dialética e a aprendizagem, pois segundo Pérez Gómez (1993, p. 50) "este leva a uma dinâmica perfeitamente influenciada, dentro dos limites pelas intervenciones precisas da aprendizagem guiado intencionalmente". Vygotsky ajuda na compreensão que tudo o que um indivíduo consegue fazer com ajuda hoje, pode obter sucesso sozinho amanhã, já que os intercâmbios o colocarão em contato com ideias, significados e intenções que serão parte de sua formação.

Complementando as contribuições, Bruner (1973) direciona seu trabalho diretamente para as atividades escolares, defendendo uma reforma curricular que visasse aprofundar o conhecimento dos alunos, onde na medida que defende a aprendizagem por descobrimento, adequada a estrutura cognitiva do aprendiz, com os conteúdos sendo trabalhados em forma de espiral, porque na medida que o tempo passe se 
retome o conteúdo, aprofundando-o, para conseguir "ir mais além da informação dada". Esta concepção implicou numa verdadeira revolução na forma de olhar a responsabilidade da escola e os processos de ensino.

Mesmo com todos os estudos que ficaram de legado do século XX acerca do processo de aprendizagem, ainda vemos que na atualidade há dificuldades de um bom desempenho do papel da escola em vários países. Isto ocorre porque segundo Annoni (2004) "pela dimensão institucional se entende o complexo de determinações políticas, econômicas, ideológicas, culturais, que regem, sancionam ou legitimam os processos estruturados do discurso pedagógico". São justamente estas instituições de ensino que estipulam como os alunos devem obter êxito escolar, onde a referida autora cita Michel Foucault que aborda essa situação como "formas sociais e políticas instituídas de saber e poder" (ANNONI, 2004 apud FOUCAULT, 1989).

$\mathrm{Na}$ análise do poder encontramos nas instituições a imposição de autoridade para exercício do controle, tomando como ponto de partida o currículo e as avaliações que são determinadas por órgãos que estão distantes dos alunos e consequentemente não conhecem seu contexto, mesmo assim determinam o conteúdo que será disponibilizado para o aprendiz.

Se analisarmos o viés político, perceberemos uma mão dupla dos estudos psicológicos, já que todo o processo de investigação serviu em alguns momentos com propósito de determinismos, ao buscar separar crianças normais das que possuíam dificuldade de aprendizagem, a imposição da divisão por faixa etária, servindo a interesses de políticas educacionais que reforçam a exclusão, dando espaço para que a escola eleja os fracassado e os bem sucedidos, servindo de controle social na medida que impõe a uns oportunidades de estarem inseridos no mercado de trabalhos exercendo melhores cargos e a outros impõe o abandono cognitivo, social e afetivo, produzindo mão de obra barata que é útil e indispensável ao sistema capitalista.

Se existem investigações para conhecer os processos que envolvem a aprendizagem, não faz sentido a falta de estrutura das instituições. O mais sensato seria que cada escola adeque os processos de ensino e aprendizagem ao seu próprio contexto 
histórico e social e não seguindo as ordens de uma base única em um país tão diverso, com realidades tão diferentes.

Annoni (2004) explica que "o Estado aparece como essa matriz moderna de individualização: nova forma de poder pastoral, estrutura sofisticada em que os indivíduos podem ser integrados mediante técnicas tanto "individualizantes", como "globalizantes". O Estado transfere sua responsabilidade para o indivíduo, através do conceito da meritocracia, inserindo-o num contexto global e controlador que determina um padrão de comportamento e a que tipo de conhecimento ele pode ter acesso.

As políticas educacionais nem sempre servem ao bem comum, assim como a utilização com respeito a aprendizagem nem sempre foram destinadas para melhorar a qualidade de ensino, porque se assim o fossem os currículos seriam discutidos e elaborados por docentes que vivenciam a realidade escolar e não por representantes que estão em atividades burocráticas, em órgãos federais que não fazem ideia dos problemas que passam as escolas rurais, quilombolas, de periferia e dos grandes centros urbanos.

Ainda existe um grave problema na formação docente, porque os professores são graduados para estarem numa sala de aula e para reproduzirem os interesses das políticas educacionais sem sequer terem consciência do que fazem, contribuindo para que o aluno esteja submisso aos interesses do Estado, conforme explica Annoni (2004) "Um corpo pode ser manipulado, formado, educado, obedece e responde, habilita um registro técnico/político mediante regulamentações e procedimentos empíricos e reflexivos para o controle de suas operações". Nesse contexto a autora refere-se aos alunos que devem sair da escola para serem obedientes ao sistema, capazes apenas de servir para produzir as demandas do Estado, usando o corpo docente como massa de manobra para atingirem esse objetivo, porque sua base de formação está estruturada na racionalidade clássica, na violência simbólica e no dialogo verticalizado, numa trajetória de sobrecarga nos professores de fazeres burocráticos dentro das instituições de ensino a ponto de não refletirem sobre o seu quefazer pedagógico, com o discurso demagogo de transformar a realidade, mas reproduzindo as práticas tradicionais cujo aluno é objeto e não sujeito. 


\section{CONSIDERAÇÕES FINAIS}

A aprendizagem é o foco do ensino, por isso todos os educadores devem refletir criticamente sobre seu papel, sobre que tipo de trabalho irá realizar para preparar os alunos para colocarem em pratica o aprendido e atuarem ativamente na sociedade globalizada.

Já não cabe mais nenhum tipo de reprodução dos interesses do Estado, desde que tomamos consciência do controle e da manipulação que se esconde por parte de interesses mercantis em transformar o espaço de aprendizagem em um funil que elege uma minoria para o sucesso. É preciso utilizar essas informações para o exercício de libertação das mentes, mediando junto aos alunos o verdadeiro processo de construção da aprendizagem, ressignificando as práticas pedagógicas que observem o sujeito epistêmico, respeitando-o e construindo junto a ele as bases da verdadeira educação.

O processo de ensinar e aprender deve estar atrelado a afetividade, para que o foco esteja baseado na relação professor aluno, na valorização dos atores educativos. Para isso, a atuação de cada profissional da educação deve se direcionar para os princípios de equidade, dando a todos as mesmas oportunidades através de uma educação baseada na criticidade sobre o entorno da escola, não se limitando a seguir um currículo descontextualizado que sobrecarrega e distrai a comunidade escolar para o verdadeiro compromisso da educação que é o de pensar e não de acumular informações.

No momento que reconhecemos o discurso de controle, exclusão e submissão, cada professor iniciará uma revolução dentro da sua sala de aula, exercendo as autonomia e flexibilidade para romper com paradigmas institucionais, selecionando conteúdos relevantes e significativos, capazes de promover a transformação social através de um ensino crítico para que nossos alunos possam romper com as correntes que os aprisionam e limitam sua aprendizagem. 


\section{REFERENCIAS}

ANNONI, M. E. Dimensión institucional del Aprendizaje: su formulación desde el pensamiento crítico de M. Foucault. In: Ponencia en II Jornada de Pensamiento Crítico "La crítica como subversión"- Secretaría de Ciencia y Tecnología. Facultad de Psicología. UNR. Rosario: Mimeo, 2004, p. 1 - 8.

BRUNER, J. S. Going Beyond the Information Given. New York: Norton, 1973.

BRUNER, J. Cultura, mente y educación. In: La educación, puerta de la cultura. (13ํe ed.) En Madrid: Aprendizaje Visor, 1996. Cap. 1, p. $14-32$.

BRUNER, J. S. La educación, puerta de la cultura. Madrid: Visor,1997.

COLOMBO, M. E.; STASIEJKO, H. Psicología: la actividad mental. Buenos Aires: Eudeba, 2001.

FOUCAULT, M. Vigiar y Castigar. Siglo XXI (I Reimpresión argentina), 1989.

PÉREZ GÓMEZ, A. Los procesos de enseñanza-aprendizaje: análisis didáctico de las principales teorías del aprendizaje. In: SACRISTÁN, G. Comprender y transformar

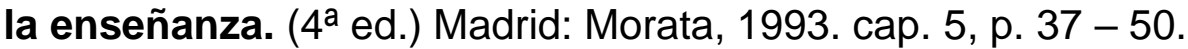

PIAGET, J. Psicología de la inteligencia. Buenos Aires: Siglo Veinte. Psicología, 1991.

TÖPF, J. Modelo estímulo respuesta. In: En Psicología. La conducta humana. Buenos Aires: Eudeba, 2006, cap. 1, p. 20 - 42.

TERÁN, O. Michel Foucault Discurso, Poder e Subjetividad. Buenos Aires, Ed. Cielo Por Asalto, 1995.

VYGOTSKY, L. Pensamiento y Lenguaje. Buenos Aires/Argentina: Fausto, 1995. 
. El desarrollo de los procesos psicológicos superiores. México: Grijalbo, 1988.

\section{APÊNDICE - REFERÊNCIAS DE NOTA DE RODAPÉ}

2. Behaviorismo são abordagens psicológicas do século $X I X$ e $X X$ para estudar o comportamento humano e animal.

3. Gestalt surgiu no início do século XX, sendo conhecida como psicologia da forma por buscar tornar explicito o que está implícito.

4. Jean Piaget (1896 - 1980) biólogo, psicólogo e epistemólogo suíço que fundou a Epistemologia Genética, teoria do conhecimento com base no estudo da gênesis psicológica do pensamento humano.

5. Lev Semyonovich Vygotsky (1896 - 1934) psicólogo russo proponente da psicologia cultural-histórica.

6. Jerome Bruner (1915 - 2016) psicólogo estadunidense estudos sobre a mente que na década de 1960 era conhecido como Revolução Cognitiva.

7. Ivan Petrovich Pavlov (1849 - 1946) fisiologista russo conhecido pelo seu trabalho sobre condicionamento clássico.

8. Burrhus Frederick Skinner (1904 - 1990) psicólogo norte-americano que desenvolveu a análise do comportamento através do condicionamento operante.

9. Max Wertheimer (1880 - 1943) psicólogo theco que se tornou um dos fundadores da Gestalt.

10. Wolfgang Köhler (1997 - 1967) psicólogo considerado o porta voz da Gestalt.

Enviado: Março, 2020.

Aprovado: Maio, 2020. 